\title{
The Swarm Satellite Constellation Application and Research Facility (SCARF) and Swarm data products
}

\author{
Nils Olsen ${ }^{1}$, Eigil Friis-Christensen ${ }^{1}$, Rune Floberghagen ${ }^{2}$, Patrick Alken ${ }^{3,4}$, Ciaran D. Beggan ${ }^{5}$, Arnaud Chulliat ${ }^{3}$, \\ Eelco Doornbos ${ }^{6}$, João Teixeira da Encarnação ${ }^{6}$, Brian Hamilton ${ }^{5}$, Gauthier Hulot ${ }^{3}$, Jose van den IJssel ${ }^{6}$, \\ Alexey Kuvshinov ${ }^{7}$, Vincent Lesur ${ }^{8}$, Hermann Lühr ${ }^{8}$, Susan Macmillan ${ }^{5}$, Stefan Maus ${ }^{4}$, Max Noja ${ }^{8}$, \\ Poul Erik H. Olsen ${ }^{1}$, Jaeheung Park ${ }^{8}$, Gernot Plank ${ }^{9}$, Christoph Püthe ${ }^{7}$, Jan Rauberg ${ }^{8}$, \\ Patricia Ritter ${ }^{8}$, Martin Rother ${ }^{8}$, Terence J. Sabaka ${ }^{10}$, Reyko Schachtschneider ${ }^{8}$, \\ Olivier Sirol $^{3}$, Claudia Stolle ${ }^{1,8}$, Erwan Thébault ${ }^{3}$, Alan W. P. Thomson ${ }^{5}$, \\ Lars Tøffner-Clausen ${ }^{1}$, Jakub Velímský ${ }^{11}$, Pierre Vigneron ${ }^{3}$, \\ and Pieter N. Visser ${ }^{6}$ \\ ${ }^{1}$ DTU Space, Technical University of Denmark, Elektrovej, DK-2800 Kgs. Lyngby, Denmark \\ ${ }^{2}$ Directorate of Earth Observation Programmes, ESRIN, via Galileo Galilei, 2, 00044 Frascati, Italy \\ ${ }^{3}$ Institut de Physique du Globe de Paris, France \\ ${ }^{4}$ National Geophysical Data Center, NOAA, USA \\ ${ }^{5}$ British Geological Survey, Murchison House, West Mains Road, Edinburgh EH9 3LA, Scotland \\ ${ }^{6}$ Delft University of Technology, The Netherlands \\ ${ }^{7}$ ETH Zurich, Switzerland \\ ${ }^{8}$ Helmholtz-Zentrum Potsdam, Deutsches GeoForschungsZentrum, 14473 Potsdam, Germany \\ ${ }^{9}$ ESTEC, The Netherlands \\ ${ }^{10}$ Planetary Geodynamics Laboratory, GSFC/NASA, Greenbelt, MD 20771, USA \\ ${ }^{11}$ Department of Geophysics, Faculty of Mathematics and Physics, Charles University in Prague, Czech Republic
}

(Received March 30, 2013; Revised June 30, 2013; Accepted July 1, 2013; Online published November 22, 2013)

Swarm, a three-satellite constellation to study the dynamics of the Earth's magnetic field and its interactions with the Earth system, is expected to be launched in late 2013. The objective of the Swarm mission is to provide the best ever survey of the geomagnetic field and its temporal evolution, in order to gain new insights into the Earth system by improving our understanding of the Earth's interior and environment. In order to derive advanced models of the geomagnetic field (and other higher-level data products) it is necessary to take explicit advantage of the constellation aspect of Swarm. The Swarm SCARF (Satellite Constellation Application and Research $\boldsymbol{F}$ acility) has been established with the goal of deriving Level-2 products by combination of data from the three satellites, and of the various instruments. The present paper describes the Swarm input data products (Level-1b and auxiliary data) used by $S C A R F$, the various processing chains of $S C A R F$, and the Level-2 output data products determined by SCARF.

Key words: Earth's magnetic field, core field, lithosphere, ionosphere, magnetosphere, electromagnetic induction, comprehensive inversion, Swarm satellites.

\section{Introduction}

Swarm, a constellation mission comprising three identical satellites to study the dynamics of the Earth's magnetic field and its interactions with the Earth system (FriisChristensen et al., 2006, 2008) is expected to be launched in late 2013. The objective of the Swarm mission is to provide the best ever survey of the geomagnetic field and its temporal evolution, in order to gain new insights into the Earth system by improving our understanding of the Earth's interior and environment.

Each of the three Swarm satellites will make highprecision and high-resolution measurements of the strength, direction and variation of the magnetic field, complemented

Copyright (C) The Society of Geomagnetism and Earth, Planetary and Space Sciences (SGEPSS); The Seismological Society of Japan; The Volcanological Society of Japan; The Geodetic Society of Japan; The Japanese Society for Planetary Sciences; TERRAPUB.

doi:10.5047/eps.2013.07.001 by precise navigation, accelerometer, plasma and electric field measurements. These observations will be provided as Level-1b data, which are the calibrated and formatted time series of e.g. the magnetic field measurements taken by each of the three Swarm satellites. These Level-1b data, as well as the higher-Level Swarm data products described in this paper, will be distributed by ESRIN (Frascati/I).

Swarm will simultaneously obtain a space-time characterisation of both the internal field sources in the Earth and the ionospheric-magnetospheric current systems. The research objectives assigned to the mission are: (a) studies of core dynamics, geodynamo processes, and core-mantle interaction; (b) mapping of the lithospheric magnetisation and its geological interpretation; (c) determination of the 3-D electrical conductivity of the mantle; and (d) investigation of electric currents flowing in the magnetosphere and ionosphere.

A challenging part, however, is the separation of the var- 
ious sources (in the core, lithosphere, ionosphere, magnetosphere etc.) which in total yields the measured magnetic field. A constellation consisting of several satellites, like Swarm, opens new possibilities for exploring the geomagnetic field from space beyond those achievable with singlesatellites. At first glance one would expect that using simultaneous data from $N$ satellites results in a reduction of the error of geomagnetic field models by $\sqrt{N}$, since the amount of data is increased by $N$ compared to one single satellite. This error reduction by $\sqrt{N}$ of course only holds if the data are statistically independent, which is highly idealistic and unrealistic since the main limiting factor for improved field modelling is not the measurement error but the dynamic behaviour of external sources. Treating data from a constellation of $N$ satellites in a "single-satellite" approach thus typically results in an improvement of the model error by less than $\sqrt{N}$. However, if explicit advantage is taken of the constellation, there is some potential for model improvement better than $\sqrt{N}$. A constellation of three satellites can do more than three single satellites, and therefore a (smart) combination of data from all three satellites, and of the various instruments, allows for taking full advantage of the Swarm constellation. Analysis of the Swarm data will greatly improve existing and provide new models of the near-Earth magnetic field of high resolution and authenticity compared to what is possible with singlesatellite missions like Ørsted (Olsen, 2007) and CHAMP (Reigber et al., 2005).

In recognition of the large effort needed to extract the various types of scientific information from the complex set of observations a group of institutions and organisations have joined the SMART consortium (Swarm Magnetic and Atmospheric Research Team). The purpose of the consortium is to contribute to the optimal science return from the Swarm mission by a coordinated effort to exploit the constellation aspects of this unique mission. This effort is obviously in accordance with ESA's aim of providing the scientific community with the best possible products from the Swarm mission, and it was decided to establish a Swarm SCARF (Satellite Constellation Application and Research $\boldsymbol{F}$ acility), with the purpose of deriving commonly used scientific models and quantities, the so-called Level-2 products and make them available to the scientific community at large. Advanced Swarm-derived models of the geomagnetic field and other Level-2 data products are determined from the Level-1b data and auxiliary (i.e. non-Swarm) data and provide the prospect of investigating hitherto undetected features of the Earth's interior.

SCARF (sometimes also called "Level-2 Processing System", $L 2 P S)$ comprises in its present form a joint effort between the six European partners: DTU (Lyngby/DK), TU Delft (Delft/NL), BGS (Edinburgh/GB), ETH (Zürich/CH), GFZ (Potsdam/D) and IPGP (Paris/F) with contributions from CUP (Prague/CZ), NOAA (Boulder/USA) and GSFC/NASA (Greenbelt/USA). The team behind SCARF has designed and implemented algorithms to derive advanced models of the geomagnetic field describing sources in the core, lithosphere, ionosphere and magnetosphere, models of the electrical conductivity of Earth's mantle and time series of thermospheric wind and density at the positions of the Swarm satellites. These models, which are state-of-the-art implementations of current knowledge, are intended to facilitate and increase the use of the Swarm data by a much wider community than the one represented in the SMART consortium itself.

The work performed by $S C A R F$ is a major extension on the "End-To-End" mission simulation that has been performed during Phase A of the Swarm mission, the results of which have been published in a special issue (Vol. 58 No. 4, 2006) of Earth, Planets and Space (cf. Olsen et al., 2006 for an overview).

The present paper describes the Swarm input data products (Level-1b and auxiliary data) used by $S C A R F$, the various processing chains of $S C A R F$, and the Level-2 output data products determined by $S C A R F$ and distributed by ESA through the PDGS (Payload Data Ground Segment) at ESRIN.

The content of the paper is as follows: Section 2 summarizes the various Level-1b data, with emphasis on the $1 \mathrm{~Hz}$ time series of the magnetic field observations. Section 3 describes the various processing chains and resulting Level-2 data products. All processing chains have been tested using synthetic data from a full mission simulation; the creation of this synthetic data set is described in Section 4. Data processing time-line and data availability are discussed in Section 5 .

\section{Swarm Level-1b Products}

The Level-1b products of the Swarm mission contain time-series of quality-screened, calibrated, and corrected measurements given in physical, SI units in geo-localized reference frames. Level-1b products are provided individually for each of the three satellites Swarm A, Swarm B, and Swarm C on a daily basis, i.e. each product contains all available data of that day from 00:00 until (but not including) 24:00 UT time. An example illustrating the filenaming convention of Swarm Level-1b $1 \mathrm{~Hz}$ magnetic product MAGX_LR from 23. February 2013 is given in Fig. 1.

Table 1 lists the various Level-1b data products. Ephemeris Products are data obtained by the GPS receiver, the accelerometer and the star tracker; the Magnetic Products contain measurements taken by the two magnetometers (augmented with position and attitude measured by the star tracker), while the Plasma Products contain data obtained by the Thermal Ion Imager and the Langmuir probe. Most Level-1b products are provided in the Common Data Format (CDF, see Goucher and Mathews (1994) and http: / / cdf.gsfc.nasa.gov/) which is a file format optimized for storing time series, although data from the GPS receiver are provided in the RINEX and SP3 formats as is typical for these kind of data.

Probably the most important Level-1b product, MAGx_LR (where " $\mathrm{x}$ " is a placeholder for " $\mathrm{A}$ ", " $\mathrm{B}$ ", or " $\mathrm{C}$ " indicating the satellite), contains $1 \mathrm{~Hz}$ time series with magnetic field observations from each of the three satellites. The content of the product is described in more detail in Table 2. In addition to time and position it contains the magnetic scalar intensity $F$ and the three components of the magnetic vector $\mathbf{B}_{\mathrm{NEC}}=\left(B_{\mathrm{N}}, B_{\mathrm{E}}, B_{\mathrm{C}}\right)$ in the North-East-Center (NEC) local Cartesian coordinate frame (where $B_{\mathrm{N}}$ is the component 


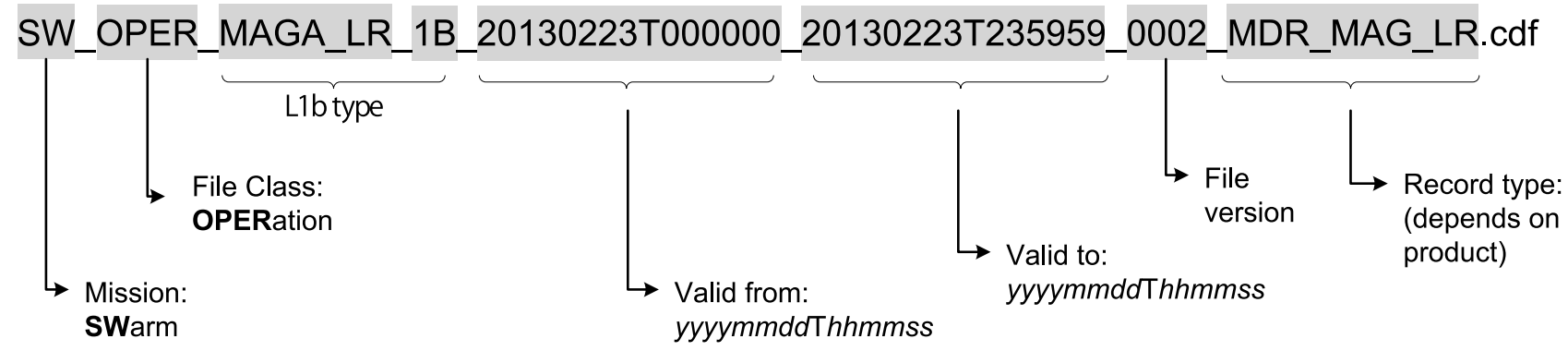

Fig. 1. Example illustrating the filename of the Swarm-A Level-1b low-rate magnetic product MAGx_LR from 23. February 2013.

Table 1. Swarm Level-1b products. The "x" in the product name is a placeholder for "A", "B", or "C" indicating the satellite.

Ephemeris Products

\begin{tabular}{|c|c|c|c|}
\hline Type & Descriptive Name & Format & Contents \\
\hline GPSX_RO & RINEX Observations & RINEX 3.0 & Processed and corrected data from the GPS receiver, $0.1 \mathrm{~Hz}$ sampling \\
\hline GPSx_RN & RINEX Navigation data & RINEX 3.0 & GPS navigation data from the GPS receiver \\
\hline GPSXNAV & Navigational Solution & SP3 & $\begin{array}{l}\text { Position and velocity from on-board GPS receiver navigational solution, } \\
1 \mathrm{~Hz} \text { sampling }\end{array}$ \\
\hline MODX_SC & $\begin{array}{l}\text { Medium-Precision Orbit } \\
\text { Determination }\end{array}$ & SP3 & $\begin{array}{l}\text { Position and velocity from automated, medium-precision orbit determi- } \\
\text { nation based on GPSx_RO data, } 1 \mathrm{~Hz} \text { sampling }\end{array}$ \\
\hline STRXATT & Attitude & $\mathrm{CDF}$ & $\begin{array}{l}\text { Processed and corrected attitude information of the spacecraft frame, } \\
\text { from the Star Tracker, } 1 \mathrm{~Hz} \text { sampling }\end{array}$ \\
\hline $\mathrm{ACCX} \_\mathrm{PR}$ & $\begin{array}{l}\text { Non-gravitational Accel- } \\
\text { erations }\end{array}$ & $\mathrm{CDF}$ & $\begin{array}{l}\text { Pre-processed linear and angular, non-gravitational acceleration mea- } \\
\text { surements from the accelerometer (Fully calibrated and corrected lin- } \\
\text { ear, non-gravitational accelerations are provided as Level-2 product } \\
\text { ACCXPOD_2_), } 1 \mathrm{~Hz} \text { sampling }\end{array}$ \\
\hline
\end{tabular}

\begin{tabular}{|c|c|c|c|}
\hline Type & Descriptive Name & Format & Contents \\
\hline MAGx_LR & $\begin{array}{l}\text { Low Rate }(1 \mathrm{~Hz}) \text { magnetic } \\
\text { data }\end{array}$ & $\mathrm{CDF}$ & $\begin{array}{l}\text { Calibrated and corrected magnetic vector and scalar measurements, } \\
\text { interpolated to UTC seconds and provided in VFM sensor as well as } \\
\text { in NEC frame }\end{array}$ \\
\hline MAGX_HR & $\begin{array}{l}\text { High Rate }(50 \mathrm{~Hz}) \text { mag- } \\
\text { netic data }\end{array}$ & $\mathrm{CDF}$ & $\begin{array}{l}\text { Calibrated and corrected magnetic vector measurements, provided in } \\
\text { VFM sensor as well as in NEC frame }\end{array}$ \\
\hline MAGX_CA & Magnetic calibration data & $\mathrm{CDF}$ & Magnetic scalar calibration data for long-term VFM analysis \\
\hline
\end{tabular}

Plasma Products
\begin{tabular}{|c|l|l|l|}
\hline Type & Descriptive Name & Format & Contents \\
\hline EFIx_PL & Plasma data & CDF & $\begin{array}{l}\text { Processed and corrected plasma measurements from the EFI instru- } \\
\text { ments including electric field vector, plasma density, plasma electron } \\
\text { and ion temperatures, 2 Hz sampling }\end{array}$ \\
TIIx_CA & $\begin{array}{l}\text { Langmuir probe calibra- } \\
\text { tion data } \\
\text { Thermal Ion Imager cali- } \\
\text { bration data }\end{array}$ & CDF & $\begin{array}{l}\text { Offset determination mode data and corresponding estimated calibra- } \\
\text { tion parameters } \\
\text { Daily calibration parameters used for monitoring and optimisation of } \\
\text { the TII instrument performance }\end{array}$ \\
\hline
\end{tabular}

towards geographic North, $B_{\mathrm{E}}$ is the component towards geographic East, and $B_{\mathrm{C}}$ is the component towards the center of the Earth). In addition, the magnetic vector $\mathbf{B}_{\mathrm{VFM}}$ in the instrument frame of the Vector Field Magnetometer (VFM) is given, where

$$
\mathbf{B}_{\mathrm{NEC}}=\underline{\underline{R}}_{q} \underline{\underline{R}}_{3} \mathbf{B}_{\mathrm{VFM}}
$$

with

$$
\begin{aligned}
\underline{\underline{R}}_{3}= & \left(\begin{array}{ccc}
\cos \gamma & -\sin \gamma & 0 \\
\sin \gamma & \cos \gamma & 0 \\
0 & 0 & 1
\end{array}\right)\left(\begin{array}{ccc}
\cos \beta & 0 & \sin \beta \\
0 & 1 & 0 \\
-\sin \beta & 0 & \cos \beta
\end{array}\right) \\
& \times\left(\begin{array}{ccc}
1 & 0 & 0 \\
0 & \cos \alpha & -\sin \alpha \\
0 & \sin \alpha & \cos \alpha
\end{array}\right)
\end{aligned}
$$


Table 2. Content of Swarm Level-1b Product MAGx_LR.

\begin{tabular}{|c|c|c|}
\hline Element & Contents & Units \\
\hline Timestamp & Time of observation & CDF_EPOCH \\
\hline Syncstatus & Time reference information & - \\
\hline Latitude & Latitude of observation in the International Terrestrial Reference Frame (ITRF) & degree \\
\hline Longitude & Longitude of observation in the ITRF & degree \\
\hline Radius & Radius of observation in ITRF & $\mathrm{m}$ \\
\hline $\mathrm{F}$ & Magnetic field intensity & $\mathrm{nT}$ \\
\hline dF_AOCS & Magnetic stray field correction intensity related to attitude control magneto-torquers & $\mathrm{nT}$ \\
\hline dF_other & Magnetic stray field correction intensity of all other sources & $\mathrm{nT}$ \\
\hline F_error & Error estimate on magnetic field intensity & $\mathrm{nT}$ \\
\hline B_VFM & Magnetic field vector in the instrument frame of the VFM magnetometer & $\mathrm{nT}$ \\
\hline$B \_N E C$ & Magnetic field vector in the NEC (North, East, Center) frame & $\mathrm{nT}$ \\
\hline dB_AOCS & $\begin{array}{l}\text { Magnetic stray field correction vector related to attitude control magneto-torquers } \\
\text { (in VFM frame) }\end{array}$ & $\mathrm{nT}$ \\
\hline dB_other & Magnetic stray field correction vector of all other sources (in VFM frame) & $\mathrm{nT}$ \\
\hline B_error & Error estimates on magnetic field vector $\mathbf{B}_{\mathrm{VFM}}$ (in VFM frame) & $\mathrm{nT}$ \\
\hline q_NEC_CRF & $\begin{array}{l}\text { Rotation from NEC frame to STR Common Reference Frame (CRF), } \\
\text { quaternion }(\mathrm{NEC} \leftarrow \mathrm{CRF})\end{array}$ & - \\
\hline Att_error & Error estimate on attitude information & degree $/ 10^{3}$ \\
\hline Flags_F & $\begin{array}{l}\text { Flags characterizing the magnetic field intensity measurement: spikes or gap in data, discrep- } \\
\text { ancy between ASM and VFM, etc. }\end{array}$ & - \\
\hline Flags_B & $\begin{array}{l}\text { Flags characterizing the magnetic field vector measurement } \mathbf{B}_{\mathrm{VFM}} \text { and } \mathbf{B}_{\mathrm{NEC}} \text { : spikes or gap in } \\
\text { data, discrepancy between ASM and VFM, etc. }\end{array}$ & - \\
\hline Flags_q & Flags characterizing the attitude information: identification of active heads, blinding, etc. & - \\
\hline Flags_Platform & $\begin{array}{l}\text { Flags characterizing the spacecraft platform information: thruster activation, lack of telemetry, } \\
\text { etc. }\end{array}$ & - \\
\hline ASM_Freq_Dev & ASM reference frequency calibration data deviation for ASM stability assessment & $\mathrm{Hz}^{1 / 2}$ \\
\hline
\end{tabular}

as the matrix describing the rotation of the magnetic field from the VFM system to the Common Reference Frame (CRF) of the star tracker $(\alpha, \beta$ and $\gamma$ are the Euler angles describing this rotation; they are provided in the Level-2 data product MSW_EUL_2_) and

$$
\underline{\underline{R}}_{q}=\left[\begin{array}{ccc}
1-2 q_{2}^{2}-2 q_{3}^{2} & 2\left(q_{1} q_{2}+q_{3} q_{4}\right) & 2\left(q_{1} q_{3}-q_{2} q_{4}\right) \\
2\left(q_{1} q_{2}-q_{3} q_{4}\right) & 1-2 q_{1}^{2}-2 q_{3}^{2} & 2\left(q_{2} q_{3}+q_{1} q_{4}\right) \\
2\left(q_{1} q_{3}+q_{2} q_{4}\right) & 2\left(q_{1} q_{4}-q_{2} q_{3}\right) & 1-2 q_{1}^{2}-2 q_{2}^{2}
\end{array}\right]
$$

as the rotation matrix from the CRF to the NEC coordinate frame, described by the quaternions $\mathbf{q}_{\mathrm{NEC}} \leftarrow \mathrm{CRF}=$ $\left[\begin{array}{llll}q_{1} & q_{2} & q_{3} & q_{4}\end{array}\right]^{\mathrm{T}}$. Finally, the magnetic field corrections (dF_AOCS, dF_other, dB_AOCS, dB_other) that have been applied to the data, error estimates (F_error, B_error, Att_error) and flags characterizing the status of the various instruments and the spacecraft are also provided.

The quality of Level-1b magnetic and plasma products MAGX_LR and EFIX_PL can be inspected using quick-look products, essentially comprising various daily and missionto-date plots designed to reveal a range of possible measurement problems (Beggan et al., 2013).

The positions provided in the Level-1b data are generated automatically as part of the Level-1b processing as "Medium Precise Orbits" (MOD) with an expected accuracy not exceeding a few meters. In case higher precision of the position is needed (or for periods where the MOD automatic calculation yields less optimal results) it is recommended to use the positions provided by the "Precise Orbit Determination" (POD) chain (Level-2 product
SP3XCOM_2_) discussed in Section 3.2.

\section{Swarm Level-2 Data Processing and Products}

Depending on the complexity of the processing, there are two types of Level-2 products, which are called Cat-1 and Cat- 2 products, respectively. Cat- 1 data processing involves complex algorithms to derive Level-2 products describing specific sources of the Earth's magnetic field like the lithospheric field or time series of the large-scale magnetospheric signal. Cat-1 products are derived by SCARF since scientific expertise is required during processing. In contrast, processing of Cat-2 products is less demanding, and therefore these products are derived by ESA on a daily basis in ESA's Swarm PDGS using algorithms designed by SCARF. The processing runs automatically, leading to product release with minimum delay; Cat- 2 products are tested for their near real time capability with processing delays of less than 1 hour. Cat-2 products are therefore suitable e.g. for space weather applications (Stolle et al., 2013).

Table 3 gives an overview of Level-2 products, and Fig. 2 shows a generic processing flow chart of a typical Level-2 chain of SCARF. Input Level-1b data (shown in green) and auxiliary data (yellow) are used in the various processing blocks (orange) to produce Level-2 products (magenta). In a final step all Level- 2 products are validated by interproduct comparison as well as comparison with independent data; details of this validation process are given in Beggan et al. (2013).

3.1 Level-2 products related to main magnetic sources Figure 3 shows the various chains of SCARF that result in Level-2 magnetic products. Most of the chains use $1-\mathrm{Hz}$ 
Table 3. The Swarm Level-2 products.

\begin{tabular}{|c|c|c|c|}
\hline Science Objective & Name & Format & Description \\
\hline $\begin{array}{l}\text { (needed for Level-1b pro- } \\
\text { cessing) }\end{array}$ & MSW_EUL_2_ & ASCII & $\begin{array}{l}\text { Time series of Euler angles describing transformation from STR-CRF to } \\
\text { VFM frame for all three Swarm satellites }(3 \times 3 \text { Euler angles })\end{array}$ \\
\hline Core field & MCO_SHA_2 _ & ASCII & Spherical harmonic model of the core field and its temporal variation \\
\hline Lithospheric field & MLI_SHA_2 _ & ASCII & Spherical harmonic model of the lithospheric field \\
\hline $\begin{array}{l}\text { Electrical conductivity of } \\
\text { the mantle }\end{array}$ & $\begin{array}{l}\text { MIN_1DM_2 } \\
\text { MIN_3DM_2 } \\
\text { MCR_1DM_2 } \\
\text { MCR_3DM_2 }\end{array}$ & $\begin{array}{l}\text { ASCII } \\
\text { ASCII } \\
\text { ASCII } \\
\text { ASCII }\end{array}$ & $\begin{array}{l}\text { 1D model of mantle conductivity } \\
\text { 3D model of mantle conductivity } \\
\text { 1D } C \text {-responses } \\
\text { 3D } C \text {-response maps }\end{array}$ \\
\hline External current systems & $\begin{array}{l}\text { MMA_SHA_2 } \\
\text { MIO_SHA_2 }\end{array}$ & CDF & $\begin{array}{l}\text { Spherical harmonic model of the large-scale magnetospheric field and its } \\
\text { Earth-induced counterpart } \\
\text { Spherical harmonic model of the daily geomagnetic variation at middle } \\
\text { latitudes (Sq) and low latitudes (EEJ) }\end{array}$ \\
\hline $\begin{array}{l}\text { Precise Orbit Determina- } \\
\text { tion (POD) }\end{array}$ & $\begin{array}{l}\text { SP3XCOM_2 } \\
\text { ACCXCAL_2 } \\
\text { ACCXPOD_2 }\end{array}$ & $\begin{array}{l}\text { SP3 } \\
\text { CDF } \\
\text { CDF }\end{array}$ & $\begin{array}{l}\text { Time series of position and velocity of the center of mass for satellite } \mathrm{x} \\
(\mathrm{x}=\mathrm{A}, \mathrm{B} \text { or } \mathrm{C}) \\
\text { Accelerometer calibration parameters for satellite } \mathrm{x} \\
\text { Time series of non-gravitational accelerations estimated for satellite } \mathrm{x}\end{array}$ \\
\hline $\begin{array}{l}\text { Magnetic Forcing of the } \\
\text { Upper Atmosphere }\end{array}$ & $\begin{array}{l}\text { ACCX_AE_2 _ } \\
\text { DNSXWND_2 _ }\end{array}$ & $\mathrm{CDF}$ & $\begin{array}{l}\text { Time series of calibrated and pre-processed accelerometer observations and } \\
\text { of aerodynamic accelerations for satellite } \mathrm{x} \\
\text { Time series of neutral thermospheric density and wind speed for satellite } \mathrm{x}\end{array}$ \\
\hline $\begin{array}{l}\text { Earth environment and } \\
\text { Space-Weather } \\
\text { (Cat-2 products) }\end{array}$ & $\begin{array}{l}\text { IBIXTMS_2F } \\
\text { TECXTMS_2F } \\
\text { FAC_TMS_2F } \\
\text { FACXTMS_2F } \\
\text { EEFXTMS_2F }\end{array}$ & $\begin{array}{l}\mathrm{CDF} \\
\mathrm{CDF} \\
\mathrm{CDF} \\
\mathrm{CDF} \\
\mathrm{CDF}\end{array}$ & $\begin{array}{l}\text { Ionospheric bubble index for satellite } \mathrm{x} \\
\text { Time series of the ionospheric total electron content for satellite } \mathrm{x} \\
\text { Time series of field-aligned currents determined from combination of } \\
\text { Swarm A and Swarm B } \\
\text { Time series of field-aligned currents (single-satellite solution) for satellite } \mathrm{x} \\
\text { Equatorial Electric Field for satellite } \mathrm{x}\end{array}$ \\
\hline
\end{tabular}

magnetic field data from each of the three Swarm satellites (Level-1b product MAGx_LR) as input (exceptions are the chains that derive models of the electrical conductivity of the Earth's mantle which rely on time series of magnetospheric and induced fields as provided as Level-2 data). Models of the core, lithospheric, non-polar ionospheric and large-scale magnetospheric fields are derived using two independent chain branches: in the Comprehensive Inversion (CI) chain these sources are co-estimated in one huge inversion process; details are given in Sabaka et al. (2013). In the Dedicated Inversion (DI) chains the various sources are determined in a sequential approach after removing models describing the other sources; there are dedicated chains for the core field (Rother et al., 2013), for the lithospheric field (Thébault et al., 2013), for deriving the daily ionospheric variation at non-polar latitudes (Chulliat et al., 2013) and for determining time-series of the large-scale magnetospheric contributions (Hamilton, 2013).

Processing of Swarm Level-1b products in order to derive Level-2 products requires auxiliary data and models, in particular indices describing the state of the Earth's environment. These auxiliary data (shown in yellow in Figs. 3 to 5) are: the 3-hour $K p$ index describing global geomagnetic activity (auxiliary data product AUX_KP__2_), hourly values of the $D s t$-index monitoring the strength of the magnetospheric ring-current (AUX_DST_2_), daily $F_{10.7}$ values of solar radio flux (AUX_F10_2_) and parameters of the Interplanetary Magnetic Field (AUX_IMF_2_). In addition, checked and corrected hourly mean values from the global network of ground magnetic observatories are provided as auxiliary data product AUX_OBS_2_; details of the data checking procedure are given in Macmillan and Olsen
(2013). Auxiliary data are used in the selection of Swarm data for deriving Level-2 products. In addition, the Comprehensive Inversion chain and the Dedicated Ionospheric chain also use magnetic observatory data in combination with the Swarm magnetic observations. Finally, observatory hourly means are also used in the validation of the magnetic Level-2 products (Beggan et al., 2013).

In addition to auxiliary data, the processing also requires auxiliary models like the IGRF (AUX_IGR_2_) or more advanced models of the core field (AUX_COR_2_) and the lithospheric field (AUX_LIT_2 $2_{-}$). Models of the electrical conductivity of the Earth's mantle (AUX_MCM_2_) and of the surface conductance of oceans and sediments (AUX_OCM_2_) are used to account for secondary, Earthinduced contributions connected to the temporal variations of magnetospheric and ionospheric origin. Finally, a model of the magnetic signature of ocean tides (AUX_MTI_2_) is provided.

In the following we briefly discuss the various Level-2 products.

Spherical Harmonic Models of the core, lithospheric, ionospheric and magnetospheric field. Models of the core field and its time changes are provided as spherical harmonic expansion coefficients in the Level-2 product $M C O \_S H A \_2$ (where "M" indicates that the product describes a Magnetic source, "CO" stands for COre field, "SHA" denotes that the model is given as an expansion of a Spherical Harmonic Analysis, and "2" refers to the fact that this is a Level-2 data product. The last character, in this example "_,", indicates the generic form of the Level-2 product; other values are " $C$ " if the product is derived in the Comprehensive Inversion chain or " $D$ " if the product is 

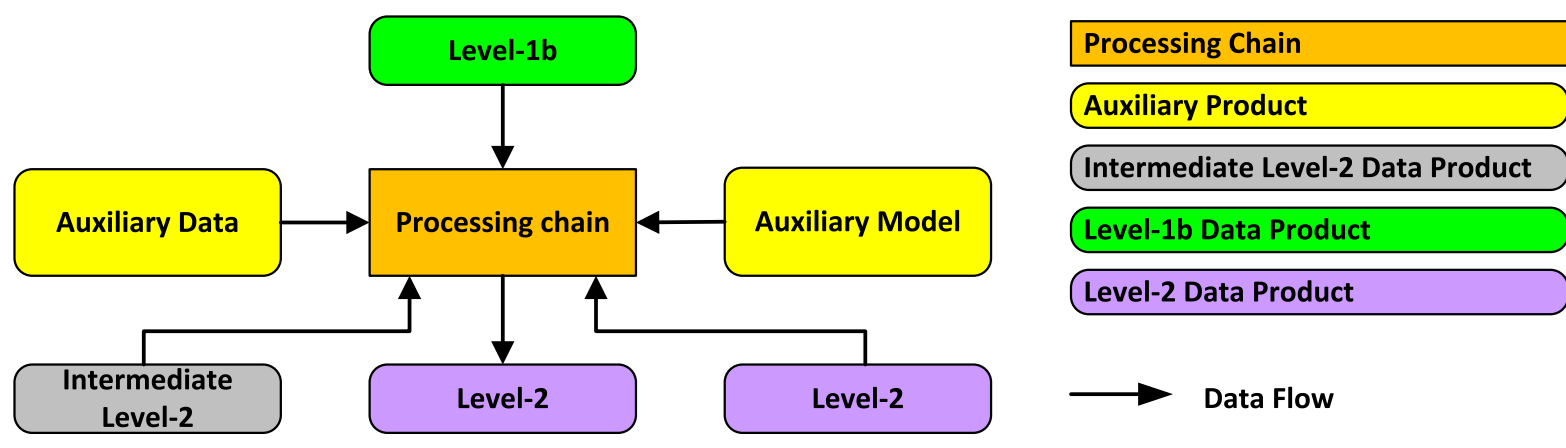

Fig. 2. Data flow in a typical Level-2 processing chain.

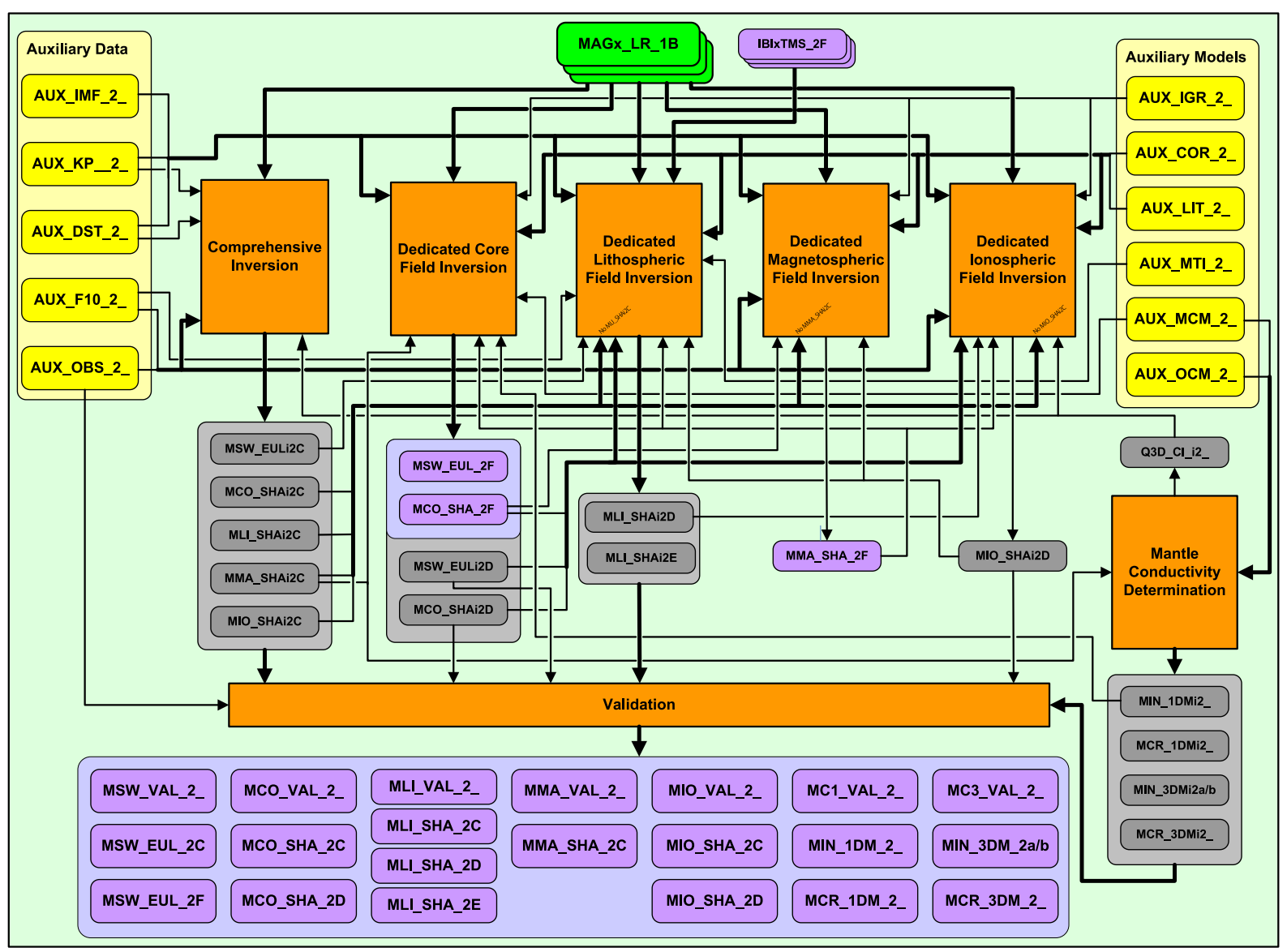

Fig. 3. Level-2 processing chains which result in magnetic Level-2 products.

derived in one of the Dedicated Inversion chains.)

The magnetic field vector, $\mathbf{B}_{\mathrm{NEC}}=-\nabla V$, is described using a magnetic scalar potential $V$ which is expanded into series of spherical harmonics. For the potential describing internal sources (in the core and lithosphere) this expansion reads

$$
\begin{aligned}
V= & a \sum_{n=N_{\min }}^{N_{\max }} \sum_{m=0}^{n}\left(g_{n}^{m} \cos m \phi+h_{n}^{m} \sin m \phi\right) \\
& \times\left(\frac{a}{r}\right)^{n+1} P_{n}^{m}(\cos \theta)
\end{aligned}
$$

where $a=6371.2 \mathrm{~km}$ is a reference radius, $(r, \theta, \phi)$ are geographic coordinates, $P_{n}^{m}$ are the associated Schmidt semi-normalized Legendre functions, $\left\{g_{n}^{m}, h_{n}^{m}\right\}$ are the Gauss coefficients describing internal sources, and $N_{\min }, N_{\max }$ are the minimum, resp. maximum, degree and order of the spherical harmonic expansion.

For the core field models these are chosen to be $N_{\min }=$ $1, N_{\max }=18$ and the time dependence of the Gauss coefficients $\left\{g_{n}^{m}(t), h_{n}^{m}(t)\right\}$ is parametrized using B-splines; however, the final product MCO_SHA_2 _ contains a series of snapshot models (corresponding to order 6 splines and 6 months separation of the spline knots). Details of the data format, and how to transform back from the snapshot representation to the original spline representation, are given in the Level-2 Product Definition Document (Swarm Level 2 Processing System Consortium, 2013).

Core field model version MCO_SHA_2C is derived in the Comprehensive Inversion chain (see Sabaka et al. (2013) 
for details), while model version MCO_SHA_2D is derived in the Dedicated Inversion chain (Rother et al., 2013).

A proper determination of the Euler angles $\alpha, \beta, \gamma$ describing the rotation between the instrument frames of the vector magnetometer and star tracker (see Eq. (2)) is only possible in-orbit. A pre-flight determination made on ground is limited e.g. by atmospheric turbulence to an accuracy of, say, 20 arc-seconds since global data coverage is required in order to obtain Euler angles within a few arc-seconds. This is only possible in-orbit. A determination of the Euler angles by co-estimation with all major contributions to the near-Earth magnetic field is made in the Comprehensive Inversion chain (Sabaka et al., 2013), and an independent determination is made in the Dedicated Core chain (Rother et al., 2013). The resulting Euler angles are provided as Level-2 data product MSW_EUL_2 (MSW_EUL_2C and MSW_EUL_2F) and will be used in the re-processing of Level-1b data by the PDGS.

Spherical Harmonic Models of the lithospheric field are provided in the Level-2 product MLI_SHA_2 _ (where "LI" stands for LIthospheric field). Similar to the core field products, model version MLI_SHA_2C is derived in the CI chain, while model MLI_SHA_2D is determined using the Revised Spherical Harmonic Cap method, as described in Thébault et al. (2013). The minimum, resp. maximum, spherical harmonic degree and order is $N_{\min }=16$ and $N_{\max }=150$.

A model of the non-polar daily geomagnetic variation caused by ionospheric currents, including their variability with season and solar flux, is given in the Level-2 product MIO_SHA_2_, where "IO" stands for IOnospheric field. Details of the dedicated chain leading to product version MIO_SHA_2D are given in Chulliat et al. (2013). Product version MIO_SHA_2C is derived in the CI chain.

Finally, time-series of spherical harmonic expansion coefficients of the large-scale magnetospheric field and its Earth-induced counterpart are provided in the Level-2 product of generic name MMA_SHA_2_. As part of the CI chain time series of the magnetospheric and induced expansion coefficients are provided with a sampling rate of 90 minutes (corresponding approximately to the orbital period of the satellites) for degree $n=1$ and order $m=0$, and with a sampling rate of 6 hours for degrees up to $n=3$ and order $m=0,1$ for the magnetospheric field and up to $n=m=5$ for the induced field. The name of the resulting product is MMA_SHA_2C. The dedicated chain (Hamilton, 2013) for deriving a related product called MMA_SHA_2F contains time series of magnetospheric and induced fields for degree $n=1$ and order $m=0,1$ with sampling rate of 90 minutes. (The last character " $F$ " in the product name indicates that this is a fast-track product which is provided without an independent regular validation as is the case for most other Level-2 products).

Level-2 data product MMA_SHA_2C of the large-scale magnetospheric field and its Earth-induced counterpart is used to determine models of electrical conductivity of the mantle, regarding both its 1-D structure (which means that conductivity is assumed to only vary with depth, resulting in Level-2 product MIN_1DM_2_, see Püthe and Kuvshinov (2013a) for details) and lateral variations of conductivity (3-D models, Level-2 product MIN_3DM_2_). The latter is derived using two independent chains, working in the frequency domain, leading to product version MIN_3DM_2a (Püthe and Kuvshinov, $2013 \mathrm{~b}$ ), or in the time domain, leading to product version MIN_3DM_2b (Velímský, 2013). Electromagnetic transfer functions ( $C$-responses) are also provided (Level-2 products MCR_1DM_2 _ and MCR_3DM_2_).

3.2 Level-2 products related to acceleration, orbit determination and thermospheric wind and density

Precise reduced-dynamic and kinematic orbit solutions for the three Swarm satellites are provided in the Level-2 products SP3XCOM_2 _ and SP3XKIN_2 . As part of this POD processing chain also the accelerometer calibration parameters (product $\mathrm{ACCXCAL}_{-} 2_{-}$) as well as nongravitational accelerations ( $\mathrm{ACCXPOD} 2_{2}$ ) are determined. Time series of thermospheric winds and density at the location of each of the three Swarm satellites are provided in the Level-2 product DNSxWND_2_. Details of the processing scheme are given in Visser et al. (2013). The data flow of the two chains that result in these Level-2 products is shown in Fig. 4.

\subsection{Level-2 products related to the Earth environment and space weather (Cat-2 products)}

Figure 5 shows the processing chains that result in the Cat-2 Level-2 products (listed in the bottom part of Table 3 ). All Cat-2 products are provided as daily CDF files (similar to most of the Level-1b products) since they all contain time-series of a certain geophysical quantity.

Time series of an Ionospheric Bubble Index (IBI), derived using magnetic and plasma observations from each of the three satellites, are provided in IBIxTMS_2F. Details of the processing can be found in Park et al. (2013). Time series of the ionospheric and plasmaspheric Total Electron Content (TEC) as determined by each of the three satellites are provided in the product TECXTMS_2F. The implemented algorithm for TEC determination is identical to that described by Noja et al. (2013). The processing schemes resulting in time series of Field-Aligned Currents (FAC) as provided in FACXTMS_2F (single satellite solution), resp. FAC_TMS_2F (obtained by combining data from Swarm A and B) are described in Ritter et al. (2013).

Dayside Eastward Equatorial Electric Field (EEF) values are derived for each equatorial crossing of each satellite $(\mathrm{x}=\mathrm{A}, \mathrm{B}$, or $\mathrm{C})$ and are provided in the product EEFxTMS_2F. More details on that chain are given in Alken et al. (2013).

\section{Development and Test of the Swarm SCARF}

The various Cat- 1 chains of SCARF have been tested using synthetic Level-1b data from a full 4.5 year long simulation of the Swarm mission. Since it is very difficult, if not impossible, to verify product requirements in-orbit with real data (because the reference models, the "true world", which are needed to compare the estimated models with, are not known) the performance of each chain has been investigated using synthetic data. The quality of the estimated magnetic Level-2 products is assessed against the performance requirements as listed in Table 4 using the same criteria as in the similar study of Olsen et al. (2006): 


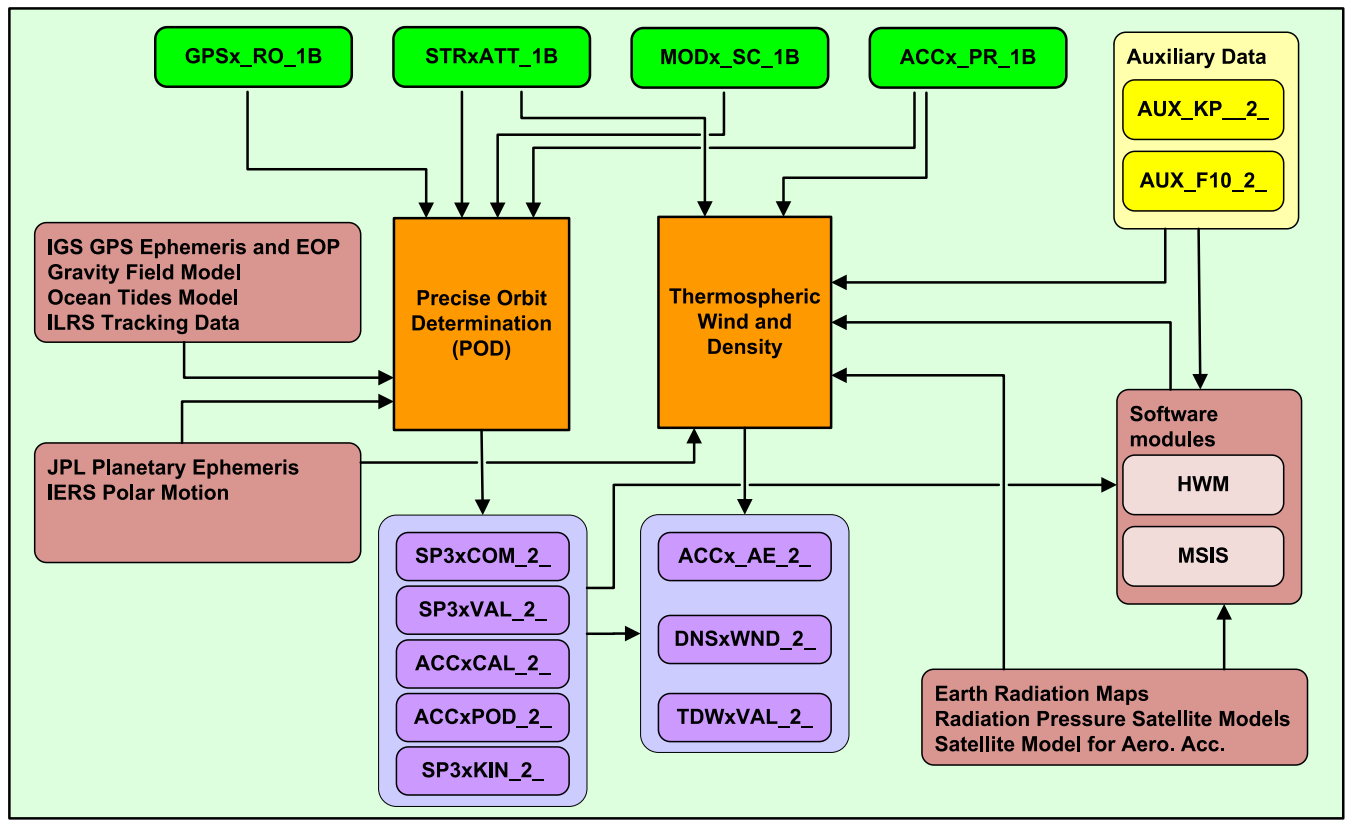

Fig. 4. Level-2 processing chains that result in precise orbits and thermospheric Level-2 products.

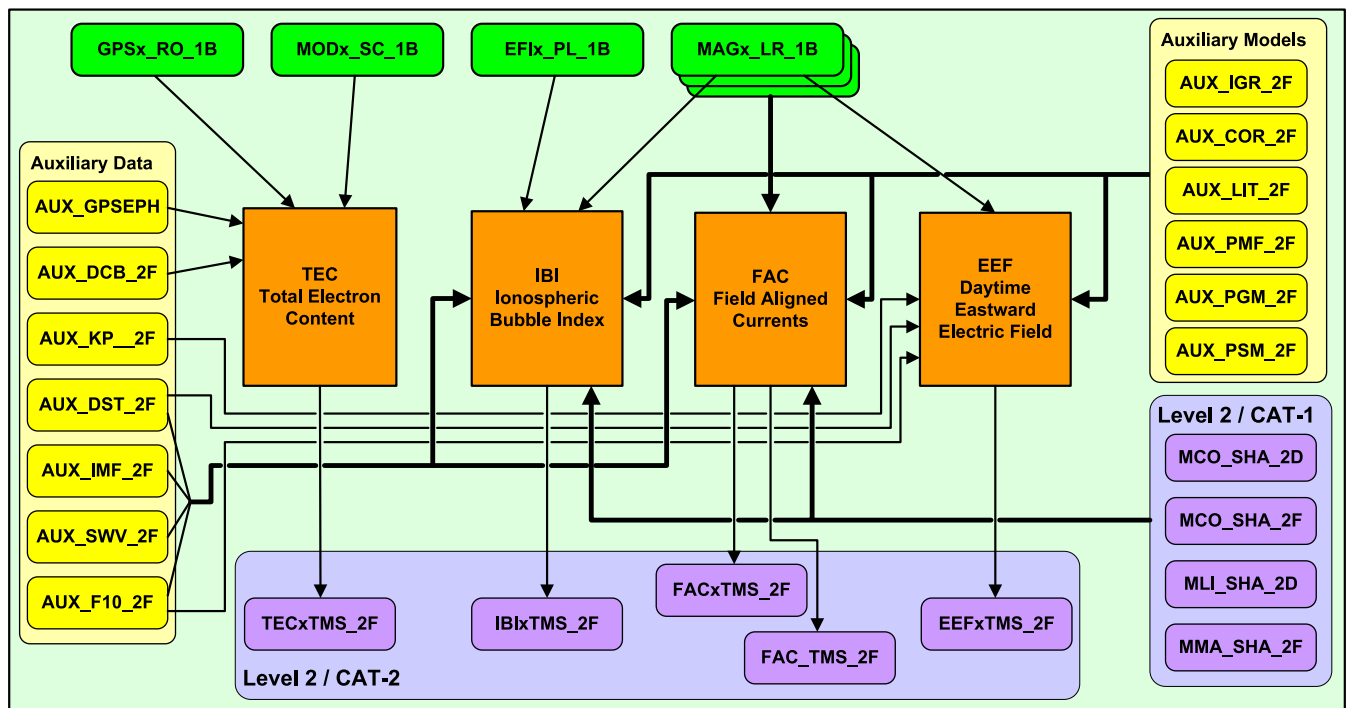

Fig. 5. Level-2 processing chains related to the Earth environment and space weather (Cat-2 products).
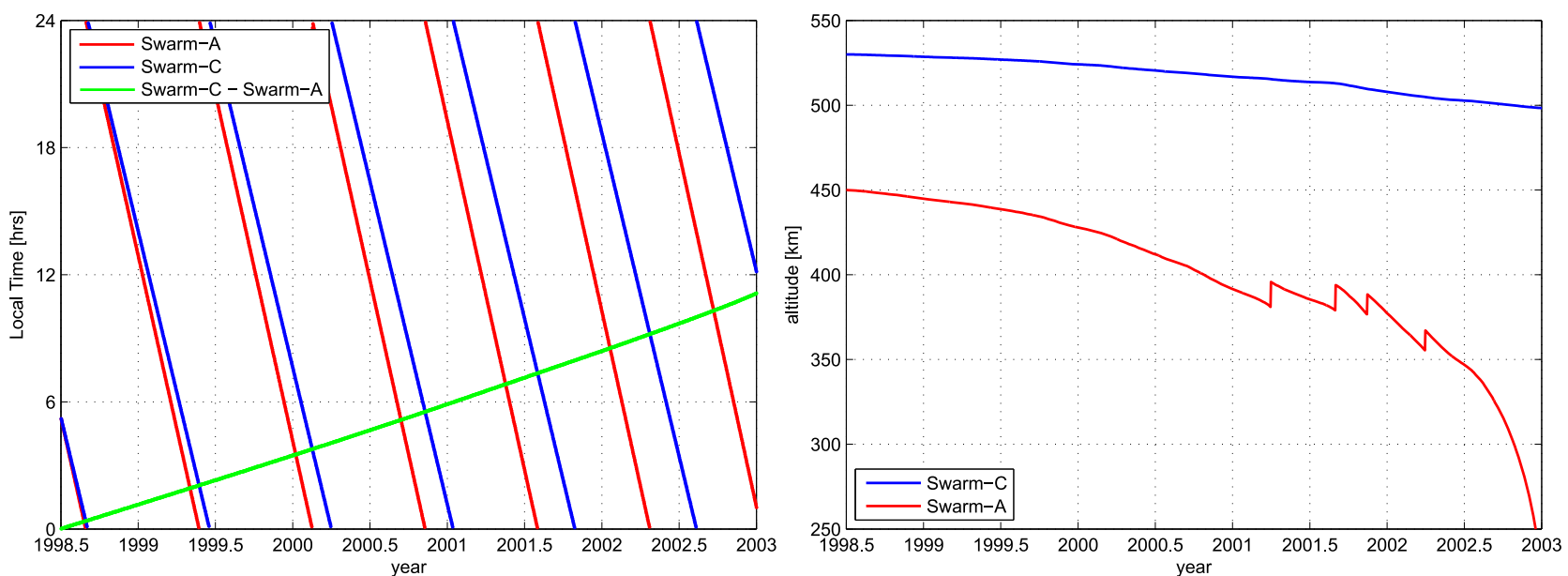

Fig. 6. Left: Local Time, Local Time difference between the upper satellite and the lower pair. Right: satellite altitude vs. time. 
- Difference in spectra, degree error, and accumulated error. The Mauersberger-Lowes spectrum (degree variance)

$$
R_{n}(r)=(n+1)\left(\frac{a}{r}\right)^{2 n+4} \sum_{m=0}^{n}\left[\left(\Delta g_{n}^{m}\right)^{2}+\left(\Delta h_{n}^{m}\right)^{2}\right]
$$

of the differences between the true (i.e. input) and the estimated model coefficients, $\Delta g_{n}^{m}, \Delta h_{n}^{m}$, in combination with the spectrum of the input model, has been used to evaluate an estimated model. Degree error is defined as $\sqrt{R_{n}}$, and accumulated error at degree $N$ is defined as $\sqrt{\sum_{n=n_{\min }}^{N} R_{n}}$.

- Degree correlation

$$
\rho_{n}=\frac{\sum_{m=0}^{n}\left[g_{n, e}^{m} g_{n, t}^{m}+h_{n, e}^{m} h_{n, t}^{m}\right]}{\sqrt{\sum_{m=0}^{n}\left[\left(g_{n, e}^{m}\right)^{2}+\left(h_{n, e}^{m}\right)^{2}\right] \sum_{m=0}^{n}\left[\left(g_{n, t}^{m}\right)^{2}+\left(h_{n, t}^{m}\right)^{2}\right]}}
$$

(Langel and Hinze, 1998, eq. (4.23)), where $g_{n, e}^{m}$ and $h_{n, e}^{m}$ are from the estimated model and $g_{n, t}^{m}$ and $h_{n, t}^{m}$ are from the input model, has also been used to evaluate a spherical harmonic model. Models are considered compatible up to that degree $n$ where $\rho_{n}$ drops below 0.7 .

- Sensitivity matrix is the relative error of each coefficient in a degree versus order matrix:

$$
S(n, m)=\left\{\begin{array}{l}
100 \frac{h_{n, e}^{m}-h_{n, t}^{m}}{\sqrt{\frac{1}{2 n+1} \sum_{m=0}^{n}\left[\left(g_{n, t}^{m}\right)^{2}+\left(h_{n, t}^{m}\right)^{2}\right]}}, \text { for } m<0 \\
100 \frac{g_{n, e}^{m}-g_{n, t}^{m}}{\sqrt{\frac{1}{2 n+1} \sum_{m=0}^{n}\left[\left(g_{n, t}^{m}\right)^{2}+\left(h_{n, t}^{m}\right)^{2}\right]}}, \text { for } m \geq 0 .
\end{array}\right.
$$

$S(n, m)$ represents the percentage degree-normalized error in a recovered coefficient of degree $n$ and order $m$.

- Global maps of field differences (for instance of $B_{r}$ ) between the input and the estimated model are used to find geographically confined deficiencies in the estimated models, for instance in connection with the polar gaps.

- Finally, the quality of time series (like those of the magnetospheric and induced spherical harmonic expansion coefficient) is assessed for various target periods using Squared Coherency $\operatorname{coh}^{2}$ : If $F(\omega)$ and $G(\omega)$ are the Fourier transform of the two time series $f(t)$ and $g(t)$ and $F(\omega)^{*}$ is the complex conjugate of $F(\omega)$ then squared coherency at frequency $\omega$ is defined as

$$
\operatorname{coh}^{2}=\frac{\left\langle F(\omega) G(\omega)^{*}\right\rangle\left\langle G(\omega) F(\omega)^{*}\right\rangle}{\left\langle F(\omega) F(\omega)^{*}\right\rangle\left\langle G(\omega) G(\omega)^{*}\right\rangle}
$$

with $\left\langle F(\omega) G(\omega)^{*}\right\rangle$ and $\left\langle G(\omega) F(\omega)^{*}\right\rangle$ as the crossspectra and $\left\langle F(\omega) F(\omega)^{*}\right\rangle$ and $\left\langle G(\omega) G(\omega)^{*}\right\rangle$ as the auto-spectra of $f(t), g(t)$ (e.g. eq. (20) of Olsen, 1998).
At the beginning of the SCARF activity the launch of the Swarm satellites was still scheduled for 2010. In order to have similar ambient conditions, but access to actual input values to parametrize e.g. atmospheric drag or Earth rotation variations, we simulated a launch on July 1, 1998, 00:00 UT, which is approximately one solar cycle (11 years) before the anticipated launch in 2010 .

The performed simulation is described in more detail in Olsen et al. (2007), which is an extension of the work of Olsen et al. (2006). In a first step we calculated synthetic orbits. We assumed all three satellites to be in circular nearpolar orbits with injection altitude of $h_{0}=450 \mathrm{~km}$ altitude and orbital inclination $i=87.4^{\circ}$ for the lower pair (Swarm satellites A and B) and of $h_{0}=530 \mathrm{~km}$ altitude and orbital inclination $i=88^{\circ}$ for the third satellite Swarm C. The two lower satellites were assumed separated in longitude by $1.4^{\circ}$. They are not exactly side-by-side (which would imply collision risk near the poles) but are shifted along-track by a time lag between 2 and 10 seconds. This simulates the requirement that "The maximum time difference between Swarm A and Swarm B when crossing the equator shall be 10 seconds". The chosen orbital configuration is similar (though not identical) to the one that is presently foreseen for Swarm $\left(h_{0}=460 \mathrm{~km}\right.$ and $i=87.35^{\circ}$ for Swarm A and $\mathrm{B} ; h_{0}=530 \mathrm{~km}$ and $i=87.95^{\circ}$ for Swarm C, and a Local Time of the Ascending Node of about 14:30).

In order to get a lifetime of 4.5 years duration for the lower pair we included four orbit manoeuvres - similar to the ones of the CHAMP satellite: we increased the altitude of Swarm A and B by $15 \mathrm{~km}$ on April 1, 2001 and September 1,2001 , respectively, and by $12 \mathrm{~km}$ on November 15 , 2001 and April 1, 2002, respectively. The obtained Local Time, the Local Time difference between the upper satellite and the lower pair, and satellite altitude as a function of time are shown in Fig. 6.

Magnetic field data generation follows mainly the approach described in Olsen et al. (2006) with updates given in Olsen et al. (2007). The various input models have been designed in the following way: The core field is taken from the GRIMM model (Lesur et al., 2010) for the years 2003 to 2008 , but shifted by 5 years (i.e. to 1998.0 to 2003.0 ) in order to be compatible with the simulation period. The lithospheric input model contains spherical harmonic expansion coefficients up to degree and order 250. Degrees $n=14$ and 15 are taken from model POMME-6.1, degrees $n=16$ to 90 are taken from model MF7, and degrees 91 to 250 are taken from model NGDC-720 (version 3p1) scaled by factor 1.1. See http://geomag.org/models/index.html for more information on these models. The magnetospheric field contribution is simulated using an hour-by-hour spherical harmonic analysis of world-wide distributed observatory hourly mean values of the years 1997-2002 in dipole-latitude and magnetic local time. Expansion coefficients of degrees $n=1, \ldots, 3$ and order $m=0, \ldots, 1$ have been determined. Secondary, Earth-induced fields are determined (up to $n=15$ ) from those primary coefficients using the 3D mantle conductivity model, including oceans, discussed in Kuvshinov et al. (2006). The input model describing the ionospheric primary field is taken from CM4 
Table 4. Product requirements for magnetic Level-2 products.

\begin{tabular}{|c|c|c|}
\hline Product & Target Requirement & Threshold Requirement \\
\hline $\begin{array}{l}\text { Core field (MCO), first time derivative (secular } \\
\text { variation) at ground, } n=2-16 \text {, averaged over } \\
\text { time }\end{array}$ & $1 \mathrm{nT} / \mathrm{yr}$ & $3 \mathrm{nT} / \mathrm{yr}$ \\
\hline $\begin{array}{l}\text { Lithospheric field (MLI), accumulated error at } \\
\text { ground, } n=16-150\end{array}$ & $40 \mathrm{nT}$ & $120 \mathrm{nT}$ \\
\hline $\begin{array}{l}\text { Ionospheric field (MIO), average relative error on } \\
\text { ground }\end{array}$ & $10 \%$ globally & $10 \%$ at magnetic latitudes below $\pm 55^{\circ}$ \\
\hline Magnetospheric field (MMA) & $\begin{array}{l}\text { Squared coherency } \mathrm{coh}^{2}>0.8 \text {, though } \\
>0.95 \text { for } n=1\end{array}$ & $\begin{array}{l}\text { Squared coherency } \mathrm{coh}^{2}>0.8, \text { though } \\
>0.75 \text { for } n=1\end{array}$ \\
\hline Mantle conductivity (MIN) & $\begin{array}{l}1 / 2 \text { order of magnitude error, though } \\
1 / 4 \text { order of magnitude at depths } 400- \\
1500 \mathrm{~km}\end{array}$ & $\begin{array}{l}1 \text { order of magnitude error, though } \\
1 / 2 \text { order of magnitude at depths } \\
400-1500 \mathrm{~km}\end{array}$ \\
\hline
\end{tabular}

(Sabaka et al., 2004) while the secondary, induced, field is calculated from those primary coefficients using the same 3D mantle conductivity model as for the magnetospheric induced field. Finally, we added synthetic noise based on CHAMP experience. We assumed correlated random noise of standard deviation $(0.10 .07,0.07) \mathrm{nT}$ for $\left(B_{\mathrm{N}}, B_{\mathrm{E}}, B_{\mathrm{C}}\right)$, in agreement with the Swarm performance requirements.

The magnetic field vector in the Level-1b CDF files is given both in the NEC coordinate frame and in the VFM frame of the vector magnetometer. In order to transform the synthetic data to the VFM frame we have arbitrarily chosen the (input) Euler angles $(\alpha=-1724, \beta=$ $3488, \gamma=-6184)$ arcsecs for Swarm A, $(\alpha=808, \beta=$ $-434, \gamma=-1234)$ arcsecs for Swarm B and $(\alpha=$ 2222, $\beta=2991, \gamma=3115$ ) arcsecs for Swarm C.

The various input (reference) models are available at ftp.space.dtu.dk/data/ magnetic-satellites / Swarm / SCARF /TDS-1/ Reference/ while the synthetic $1 \mathrm{~Hz}$ Level-1b data product MAGx_LR files can be found at ftp.space. dtu.dk / data / magnetic-satellites/Swarm/ SCARF/TDS-1/Level1b/Mag/. Further details of the results of the closed-loop modelling tests to check each chain meets the performance requirements can be found in the respective references and papers in this volume.

\section{Swarm Processing Time-line and Data Avail- ability}

The processing of Swarm data into Level-1b and Level-2 products is generally performed as soon as the appropriate input data are available. As baseline, data from the Swarm satellites themselves are downlinked on a daily basis (a more frequent downlink, in particular for making Swarm data more suitable for space-weather applications, is under consideration), however, the various processing steps may require certain auxiliary data inputs and/or a significant time-span of Swarm input data in order to produce high quality output products. Consequently the Swarm data processing time-line is as follows:

- Three days (72 hours) after downlink Swarm Level-1b data are processed

- Next working day

Swarm Level-2 Quick-Look (MAGx_QL_2 and EFIx_QL_2_), Fast-Track Magnetospheric (MMA_SHA_2F) and all Cat-2 data products (which require up to 2 hours of processing time) are processed - Up to three weeks later

Swarm Level-2 Products regarding Precise Orbit Determination (SP3XCOM_2_), Accelerometer data (ACCXCAL_2 , ACCXPOD_2 , ACCX_AE_2_), and Thermospheric (Neutral) Density and Winds (DNSXWND_2_), are processed

- Every three months

Swarm Level-2 Fast-Track core field and Euler angles products (MCO_SHA_2F and MSW_EUL_2F) are processed

\section{- Every year}

Every year-plus a few extra times in reduced form during the first year of the mission-the Swarm Level-2 magnetic models are estimated and evaluated. The estimations are performed in two parallel processing chains:

- The Comprehensive Inversion (MSW_EUL_2C, MCO_SHA_2C, MLI_SHA_2C, MMA_SHA_2C, MIO_SHA_2C) and Mantle Conductivity estimations (MIN_1DM, MIN_3DM, MCR_1DM, MCR_3DM) each with a processing time of one month

- The Dedicated Inversions consisting of (in sequence, each step with a processing time of one month)

* Core field inversion (MCO_SHA_2D)

* Lithospheric field inversion (MLI_SHA_2D)

* Ionospheric field inversion (MIO_SHA_2D).

All estimated models are subject to an evaluation andwhen parallel models are available-cross-comparisons which will be documented in the Swarm Level-2 Validation Products (MyY_VAL_2_) with a processing time of up to one month.

Level-1b and Level-2 data are available at http: //earth.esa.int/swarm.

\section{Conclusions}

The Swarm mission is devoted to provide the best ever absolute measurements of the geomagnetic field. Its various instruments have been selected in order to optimize the scientific interpretation of the measurements in terms of the various sources of the magnetic field. In recognition of the large effort needed to extract the various types 
of scientific information from the complex set of observations a group of institutions and organisations have joined the SMART consortium (Swarm Magnetic and Atmospheric Research Team). The consortium has decided to contribute to the optimal science return from the mission by supporting the creation of a Swarm SCARF (Satellite Constellation Application and $\boldsymbol{R}$ esearch $\boldsymbol{F}$ acility), with the purpose of deriving commonly used scientific models and parameters, the so-called Level-2 products and make them available to the scientific community at large.

During the 3-year long development phase of SCARF the various processing chains have been optimized and thoroughly tested, demonstrating that the facility is ready to enter the data exploitation phase and process real Swarm data. It is believed that some of the results of the SCARF exercise may also be of relevance for future Earth Science constellation missions that undoubtedly will be implemented.

Acknowledgments. The Development of Swarm SCARF has been funded by ESA through contract No. 4000102140/10/NL/JA.

\section{List of Acronyms}

\begin{tabular}{|c|c|}
\hline ASM & Absolute Scalar Magnetometer (instrument) \\
\hline $\mathrm{CDF}$ & $\begin{array}{l}\text { Common Data Format } \\
\text { (Goucher and Mathews, 1994) }\end{array}$ \\
\hline $\mathrm{CI}$ & Comprehensive Inversion \\
\hline $\mathrm{CRF}$ & Common Reference Frame (of Star Tracker) \\
\hline DI & Dedicated Inversion \\
\hline EFI & Electric Field Instrument (LP and TII) \\
\hline FAC & Field-Aligned Currents \\
\hline GPS & Global Position System (Receiver) \\
\hline ITRF & International Terrestrial Reference Frame \\
\hline LP & Langmuir Probe (instrument) \\
\hline NEC & North, East, Center coordinate frame \\
\hline MOD & Medium Precise Orbit Determination \\
\hline POD & Precise Orbit Determination \\
\hline PDGS & Payload Data Ground Segment \\
\hline RINEX & $\begin{array}{l}\text { Receiver Independent Exchange Format } \\
\text { (Gurtner and Estery, 2007) }\end{array}$ \\
\hline SP3 & $\begin{array}{l}\text { National Geodetic Survey Standard GPS Format } \\
\text { (Hilla, 2007) }\end{array}$ \\
\hline STR & Star Tracker (instrument) \\
\hline TEC & Total Electron Content of ionosphere \\
\hline TII & Thermal Ion Imager (instrument) \\
\hline VFM & Vector Field Magnetometer (instrument) \\
\hline
\end{tabular}

\section{References}

Alken, P., S. Maus, P. Vigneron, O. Sirol, and G. Hulot, Swarm SCARF equatorial electric field inversion chain, Earth Planets Space, 65, this issue, 1309-1317, 2013.

Beggan, C. D., S. Macmillan, B. Hamilton, and A. W. P. Thomson, Independent validation of Swarm Level 2 magnetic field products and
'Quick Look' for Level 1b data, Earth Planets Space, 65, this issue, 1345-1353, 2013.

Chulliat, A., P. Vigneron, E. Thébault, O. Sirol, and G. Hulot, Swarm SCARF Dedicated Ionospheric Field Inversion chain, Earth Planets Space, 65, this issue, 1271-1283, 2013.

Friis-Christensen, E., H. Lühr, and G. Hulot, Swarm: A constellation to study the Earth's magnetic field, Earth Planets Space, 58, 351-358, 2006.

Friis-Christensen, E., H. Lühr, D. Knudsen, and R. Haagmans, Swarm An Earth Observation Mission investigating Geospace, Adv. Space Res., 41(1), 210 - 216, doi:10.1016/j.asr.2006.10.008, 2008.

Goucher, G. and G. Mathews, A comprehensive look at CDF, National Space Science Data Center (NSSDC) Publication, pp. 94-07, 1994.

Gurtner, W. and L. Estery, RINEX - The Receiver Independent Exchange Format-Version 3.00, Astronomical Institute, University of Bern and UNAVCO, Boulder, Colorado, 2007.

Hamilton, B., Rapid modelling of the large-scale magnetospheric field from Swarm satellite data, Earth Planets Space, 65, this issue, 1295$1308,2013$.

Hilla, S., The extended Standard Product 3 Orbit Format (SP3-c), 2007.

Kuvshinov, A. V., T. J. Sabaka, and N. Olsen, 3-D electromagnetic induction studies using the Swarm constellation. Mapping conductivity anomalies in the Earth's mantle, Earth Planets Space, 58, 417-427, 2006.

Langel, R. A. and W. J. Hinze, The Magnetic Field of the Earth's Lithosphere: The Satellite Perspective, Cambridge University Press, Cambridge, 1998.

Lesur, V., I. Wardinski, M. Hamoudi, and M. Rother, The second generation of the GFZ reference internal magnetic model: GRIMM-2, Earth Planets Space, 62, 765-773, doi:10.5047/eps.2010.07.007, 2010.

Macmillan, S. and N. Olsen, Observatory data and the Swarm mission, Earth Planets Space, 65, this issue, 1355-1362, 2013.

Noja, M., C. Stolle, J. Park, and Lühr, Long term analysis of ionospheric polar patches based on CHAMP TEC data, Radio Sci., 48, 289-301, doi:10.1002/rds.20033, 2013.

Olsen, N., Estimation of $C$-responses $(3 \mathrm{~h}$ to $720 \mathrm{~h})$ and the electrical conductivity of the mantle beneath Europe, Geophys. J. Int., 133, 298308, 1998.

Olsen, N., Ørsted, in Encyclopedia of Geomagnetism and Paleomagnetism, edited by D. Gubbins and E. Herrero-Bervera, pp. 743-745, Springer, Heidelberg, 2007.

Olsen, N., R. Haagmans, T. J. Sabaka, A. V. Kuvshinov, S. Maus, M. E. Purucker, V. Lesur, M. Rother, and M. Mandea, The Swarm End-ToEnd mission simulator study: Separation of the various contributions to Earth's magnetic field using synthetic data, Earth Planets Space, 58, 359-370, 2006.

Olsen, N., T. J. Sabaka, and L. Gaya-Pique, Study of an improved comprehensive magnetic field inversion analysis for Swarm, DNSC Scientific Report 1/2007, Danish National Space Center, Copenhagen, 2007.

Park, J., M. Noja, C. Stolle, and H. Lühr, The Ionospheric Bubble Index deduced from magnetic field and plasma observations onboard Swarm, Earth Planets Space, 65, this issue, 1333-1344, 2013.

Püthe, C. and A. Kuvshinov, Determination of the 1-D distribution of electrical conductivity in Earth's mantle from Swarm satellite data, Earth Planets Space, 65, this issue, 1233-1237, 2013a.

Puithe, C. and A. Kuvshinov, Determination of the 3-D distribution of electrical conductivity in Earth's mantle from Swarm satellite data: Frequency domain approach based on inversion of induced coefficients, Earth Planets Space, 65, this issue, 1247-1256, 2013b.

Reigber, C., H. Lühr, P. Schwintzer, and J. Wickert, Earth Observation with CHAMP, Results from Three Years in Orbit, Springer Verlag, Berlin, 2005.

Ritter, P., H. Lühr, and J. Rauberg, Determining field-aligned currents with the Swarm constellation mission, Earth Planets Space, 65, this issue, 1285-1294, 2013.

Rother, M., V. Lesur, and R. Schachtschneider, An algorithm for deriving core magnetic field models from the Swarm data set, Earth Planets Space, 65, this issue, 1223-1231, 2013.

Sabaka, T. J., N. Olsen, and M. E. Purucker, Extending comprehensive models of the Earth's magnetic field with Ørsted and CHAMP data, Geophys. J. Int., 159, 521-547, doi:10.1111/j.1365246X.2004.02421.x, 2004.

Sabaka, T. J., L. Tøffner-Clausen, and N. Olsen, Use of the Comprehensive Inversion method for Swarm satellite data analysis, Earth Planets Space, 65, this issue, 1201-1222, 2013.

Stolle, C., R. Floberghagen, H. Lühr, S. Maus, D. J. Knudsen, P. Alken, 
E. Doornbos, B. Hamilton, A. W. P. Thomson, and P. N. Visser, Space Weather opportunities from the Swarm mission including near real time applications, Earth Planets Space, 65, this issue, 1375-1383, 2013.

Swarm Level 2 Processing System Consortium, Product specification for L2 Products and Auxiliary Products, Doc. no: SW-DS-DTU-GS-0001, 2013.

Thébault, E., P. Vigneron, S. Maus, A. Chulliat, O. Sirol, and G. Hulot, Swarm SCARF Dedicated Lithospheric Field Inversion chain, Earth Planets Space, 65, this issue, 1257-1270, 2013.

Velímský, J., Determination of three-dimensional distribution of electrical conductivity in the Earth's mantle from Swarm satellite data: Timedomain approach, Earth Planets Space, 65, this issue, 1239-1246, 2013.
Visser, P., E. Doornbos, J. van den IJssel, and J. T. da Encarnação, Thermospheric density and wind retrieval from Swarm observations, Earth Planets Space, 65, this issue, 1319-1331, 2013.

N. Olsen (e-mail: nio@space.dtu.dk), E. Friis-Christensen, R. Floberghagen, P. Alken, C. D Beggan, A. Chulliat, E. Doornbos, J. T. da Encarnação, B. Hamilton, G. Hulot, J. van den IJssel, A. Kuvshinov, V. Lesur, H. Lühr, S. Macmillan, S. Maus, M. Noja, P. E. H. Olsen, J. Park, G. Plank, C. Püthe, J. Rauberg, P. Ritter, M. Rother, T. J. Sabaka, R. Schachtschneider, O. Sirol, C. Stolle, E. Thébault, A. W. P. Thomson, L. Tøffner-Clausen, J. Velímský, P. Vigneron, and P. N. Visser 